\title{
The Access and Development of Female Academics in the University Field in Greece: University of Patras Case Study
}

\author{
Anna Asimaki ${ }^{*}$, Vasilis Zenzefilis ${ }^{1}$, Gerasimos Koustourakis ${ }^{2}$ \\ ${ }^{1}$ Department of Primary Education, University of Patras, Patras, Greece \\ ${ }^{2}$ Department of Educational Sciences and Early Childhood Education, University of Patras, Patras, Greece \\ Email: ‘asimaki@upatras.gr, basiliszenze@gmail.com,koustourakis@upatras.gr
}

Received 19 February 2016; accepted 21 March 2016; published 24 March 2016

Copyright (C) 2016 by authors and Scientific Research Publishing Inc.

This work is licensed under the Creative Commons Attribution International License (CC BY). http://creativecommons.org/licenses/by/4.0/

cc) (7) Open Access

\begin{abstract}
The aim of this paper is the investigation of the presence of women Faculty Members (w.F.M.) in the academic field of the University of Patras and the detection of their views on their choice of the academic profession and on the difficulties they face in it. 20 women, belonging to the three highest levels, participated in the research, which was conducted using semi-structured interviews. The main results showed that: 1) the presence of w.F.M. is concentrated mainly in the Schools of the Humanities and the Social Sciences and in the School of Health Sciences; 2) the entrance of the w.F.M. into the academic field did not constitute their original professional objective; 3 ) the difficulties they face in their professional career progress in the academic field are centered on the conflict between their traditional social role and their professional role and the difficulties involved in accumulating scientific capital.
\end{abstract}

\section{Keywords}

Women Faculty Members, Academics, Academic Field, Difficulties, Career

\section{Introduction}

Research whose subject matter is the presence of women in the academic field reveals these women's reduced presence as Faculty Members (F.M.) in the Universities and the difficulty of their development to higher academic positions [1]. The under-representation of women, especially in the higher teaching and administrative positions in the university field, as well as the difficulties they face, are related to three phenomena which out-

\footnotetext{
${ }^{*}$ Corresponding author.
} 
line the situation which exists in the academic field in Europe and America: The first concerns the "glass ceiling effect", which reveals the existence of an impenetrable, invisible and transparent obstacle-barrier, which is constructed of negative behaviours, attitudes and stereotypes and arrests the upward progress of women beyond a particular level in their field of work [2]. The second concerns the "horizontal and vertical distinction" at the expense of women Faculty Members (w.F.M.) and is linked to their concentration mainly in the humanistic sciences and their absence from the positive sciences (horizontal discrimination), as well as with their absence from the higher levels in the professorial and administrative hierarchy (vertical discrimination) [3]. Finally, the third phenomenon concerns the "leaking or leaky pipeline" and is linked to the premature departure of w.F.M. from the university field and their likely choice of a less demanding non-academic career ([4], p. 12).

In recent years and despite the fact that the proportion of w.F.M. has increased, the research results which focus on the developed Western world (the USA., the UK, the European Union, Australia) show that women continue to comprise a minority in the university field, concentrated in the lowest levels, limited to a narrow range of scientific disciplines, on a lower salary than their male counterparts, with fewer opportunities for promotion, with lower authorial productivity, with fewer opportunities for funding of research programmes and the receipt of less time for educational leave (see: [3] [5] [6]). More specifically, it emerges from Bagilhole's research [7] [8] that at the beginning of the $21^{\text {st }}$ century too, the field of the UK universities continues to be male dominated and to place obstacles in the way of women's promotion to high academic levels. For this reason, there is a lack of women as much at the high academic levels, as in the more prestigious universities. What's more, from Van Anders' research [9] in America with postgraduate students of both sexes who planned to follow an academic career it emerged that women considered factors such as their parental role and taking care of the upbringing of children to be obstacles to achieving this objective. Obstacles such as these appear to have an effect in Europe to a greater extent than in the USA, with the result that women are under-represented in the university field [10]. However while it seems that in the USA there is greater participation of women in the university field, from the research of Monroe et al. [11] at the University of California clear discrimination emerged at the expense of women academics, on an individual and institutional level. This discrimination was apparent due to the fact that a traditional, linear male dominated model of administration and labour prevails in the university field, which obstructs women academics from balancing work demands with family responsibilities. Consequently, as appears too in Acker's research [12] with women academics in Canada, Australia and Great Britain, many of them are discouraged from constructing an academic leadership career. So, as other relevant research from European countries such as Portugal shows, inequality of access and promotion to professorship level and appointment to administrative positions, at the expense of women, is maintained and reproduced [13].

There are similar findings concerning Greece, where, despite the increase in the proportion of w.F.M. in recent decades their more general presence in the university field is limited. Hence, in the academic year 20042005 there were 6554 male F.M. (72\%) and 2569 women (28\%) and during the academic year 2010-2011 there were 8533 men (67.6\%) and 4091 women (32.4\%) [14]. In addition, there is horizontal and vertical discrimination in relation to the two sexes in the academic profession in Greece [15]-[17]. Despite the changes regarding the gender variable in the charting of Higher Education in the economically developed countries, a contradiction prevails ([18], pp. 127-128 [19]). There is numerical superiority and high female participation in the University field, in other words a "female elite with university training", and at the same time their presence is reduced in positions of status, power and great responsibility in the academic profession ([20], p. 365 [21], p. 4).

As far as Greece is concerned, we should point out that there is a lack of recent studies which investigate in depth the restricted participation of women in the academic field, the reasons for their entrance into that field and the difficulties that w.F.M. face in the course of their academic career [15]-[17].

This research was carried out within the "microcosm" of the University of Patras, which Bourdieu calls a "scientific field". This concept constitutes a derivative concept of "field". More specifically, the "field" comprises a structured space where social reality is approached in terms of objective relationships between positions which are occupied by actors ([22], p. 64 [23], p. 157). In every field a "game" takes place and the "players" who participate in it are integrated into positions in the field according to the total mass and composition of the capital they possess ([23], p. 30). The field constitutes a space of battle and competition between new arrivals and the dominant individuals who try to defend and maintain their monopoly of power and the positions of status they possess [23] [25].

The "scientific field" constitutes a structured space with general and particular logics, with connections of powers among the actors, with stakes, with benefits, interests and strategies ([26], p. 86 [27], p. 82). Right of en- 
try to the "scientific field" for the new arrivals consists of the adequacy of the embodied theoretical resources in the form of "scientific capital" ([27], p. 119), which constitutes a particular form of "symbolic capital". This capital has value within the particular scientific field and is connected and founded in acts of knowledge and recognition by all of the fellow craftsmen-competitors who are active in the field ([28], p. 75). Bourdieu distinguishes two kinds of "scientific capital", the accumulation of which is not governed by the same rules. They are the "net scientific capital" and the "institutional scientific capital". The first is acquired through and linked to discoveries, inventions and contributions that are identifiable in relation to the progress of science. The most significant component here are the publications in high status scientific journals, which constitute proof of its validity. The "institutional" capital is acquired through special strategies and policies which demand time and are linked to the possession of high institutional positions of power within the institutions of science (heads of departments and laboratories, participation in conferences, committees and ceremonies). Institutional capital is transferred in ways that resemble the means of transfer of every "bureaucratical form" of capital, despite the fact that in many cases it is adapted to the needs of a candidate who is preferred for the particular position, which is surrounded by a "cloak of clear election" [28].

The first question which arises in connection with the entry and advancement of w.F.M. in the university field is whether these women possess the suitable weapons and tools in order to participate with some chances of success in the "game" in the specific field ([27], p. 86). For the investigation of this question, an approach to Bourdieu's theory of the concepts of "institutionalized cultural capital" and habitus is essential.

"Institutionalized cultural capital" is linked to the acquisition of study titles from educational institutions and offers the holder legal guarantee and institutional recognition ([22], p. 83).

Habitus is linked to the external determinations of the individual's conditions of existence. It is a system that is registered on the mind and body constituting a memorandum in the form of "continuous and transferable dispositions, constructed constructs which can function also as constructing constructs” ([23], p. 88). Through a process of social construction and engraving, a primary-starting point habitus is shaped, initially within the individual's family, which can potentially have the forms of the "class" as well as the "engendered" habitus [12] [30]. Habitus, as a "product of the history" of the individual, is acquired through practices and is oriented towards practical functions, produces differentiated practices depending on gender, social origin and nationality ([29], pp. 102-103, 139). This means that the entry and progression of w.F.M. in the academic-scientific field presupposes the existence on their behalf, of a habitus consistent with the field. Otherwise, they are in danger of finding themselves in a difficult position and "on the sidelines" with all the consequences which stem from this situation ([28], pp. 34-35). Consequently, the second question that arises regarding the women who attempt to enter and make progress in the academic field, concerns the existence of a harmonious, or not, meeting of gendered habitus with the whole social order of things and work positions that they seek to occupy. According to Bourdieu ([29], pp. 115-116) women being "victims" of a "symbolic violence", a violence subtle and invisible, in the sense of the arbitrary imposition of attitudes, principles, meanings and evaluations, tend historically to occupy work positions that are dependent and inferior, which are linked to "femininity" and correspond to virtues such as self-denial and devotion. Women are rarely to be found among those who possess the suitable weapons and tools, such as for example adequately accumulated scientific capital which would ensure for them, within the academic field and among their colleagues, scientific and institutional power ([28], pp. 45-46).

The objective of this paper is the depiction of the presence of w.F.M. in the field of the University of Patras and the investigation of their views, as much on the factors that pushed them into choosing an academic profession, as on the difficulties they face during their career in the particular university field.

The University of Patras was chosen since it comprises the third Greek university in terms of year of establishment as well as number of teachers and students, but which nevertheless displays a singularity. To be more specific, the University of Patras was established in 1964 and began to operate from the year 1966 with the objective of meeting the needs for the production of specialised scientists in particular sectors such as technology and research. In other words, based on the aims of its establishment, it is a purely technological university, which placed emphasis on the exact and polytechnic sciences so that its graduates could contribute to the economic and technological development of Greece. In fact, it is characteristic that the Science School was established first of all at the University of Patras in 1966 and the following year the Polytechnic School was established and began to operate. Then, in 1977 the School of Health Sciences was established offering studies in Medicine and Pharmaceuticals. These choices reveal that studies in the field of the human and social sciences, 
the corresponding School being established in 1989, didn’t alter the dominance of the scientific orientation as far as the scientific identity of the University of Patras is concerned. For this reason we regarded the University of Patras to be an interesting research field concerning the entrance, career progress and professional development of w.F.M., since, as emerges from research in the international university field, women are lacking in numbers from university departments of a scientific and polytechnic orientation [3] [5] [31].

From the approach to the international and Greek bibliography, it appears that w.F.M. face difficulties concerning their entry into and attempt to make scientific progress within the academic field due to their insufficient pure and institutional scientific capital, and the gender discrimination which exists in the university field. This is because w.F.M. as subjects of a particular historical society incorporated the principles of gendered discrimination which exist within that society, into their habitus, which then influences the way in which they perceive, think and act within the institution of the university.

In this paper we will explore the following questions with the aim of contributing, through the investigation of the difficulties and social discrimination which exist for w.F.M. in the field of the University of Patras, which has always had a clearly scientific orientation, to the tracing of the experiences of and difficulties faced by many other women in the international university field:

1) What is the composition, and distribution across levels and schools of the Faculty Members in the University of Patras according to their sex?

2) What are the views of the w.F.M. in the University of Patras concerning the reasons for their entry into the academic field?

3) What difficulties do w.F.M. face during their progress in the specific academic field?

\section{Methodology}

\subsection{Choice of Research Method}

To answer the first research question we gathered and processed the relevant data from the files of the General Directorate of Administrative Services at the University of Patras for the academic year 2011-2012. To answer the next two research questions, we conducted semi-structured interviews to study the views of specific w.F.M. in depth [32]. More precisely, in order to delve more deeply into the phenomena that concern w.F.M., such as for example the phenomena of the "glass ceiling", we chose the qualitative approach, as this constitutes a systematic and empirical search for meaning ([33], p. 5). In addition, this approach is interpretive in the sense that it is concerned with the way in which the social world is interpreted, is understood, is lived and is produced, which in the case of our study concerns w.F.M. in the academic field of the University of Patras [34]. In other words, this research was carried out in the natural environment of the phenomena being studied, which is why our findings concerning w.F.M. are indicative of the real conditions they experience and face in their everyday lives [35].

\subsection{Choice of Study Tool}

The semi-structured interview was chosen in order to carry out this research, because it offered us flexibility regarding the order and the framing of questions, which allowed the w.F.M. in the sample to define in detail their working reality at the University of Patras, and the problems that they face there [36]. In this way we could see things from the viewpoint of the particular w.F.M. who participated in the research. In addition, we chose the semi-structured interview as the basic tool for our research as: 1) it provided us with the opportunity to give clarifications for the questions in vivo and to ask for explanations when the responses were not sufficiently comprehensible [32], 2) we could cultivate a climate of trust with the w.F.M. in order to stimulate their interest in cooperating, with the result that we were able to acquire confidential facts through our direct communication with them and the greater flexibility we had in the way we structured and presented the questions [34]. And 3) through the w.F.M.'s verbal and non verbal response (tone of voice, posture, facial expressions) we could gather additional information which it would not have been possible to gain from a written answer as is the case for example with the use of a questionnaire [36].

\subsection{Research Sample}

Our sample was made up of 20 w.F.M. in the University of Patras of which 8 were Assistant Professors, 7 Asso- 
ciate Professors, 4 Professors and 1 Professor Emeritus. We chose to conduct interviews with w.F.M. who were in the 3 highest levels, excluding the level of Lecturer, so that their length of time in the university field would be enough to ensure experiences. Specifically, their average length of time in the University of Patras was 18.7 years (minimum 9 years and maximum 29 years).

Regarding the family circumstances of the w.F.M. in the sample, 15 (75\%) were married and 5 (25\%) divorced. Of these, 3 (15\%) had one child, 16 (80\%) had 2 children and finally one w. F.M. (5\%) was childless. Their average age was 52 years old (the youngest was 48 and the oldest was 66).

Then, as far as the profession of the spouses of the w.F.M. in the sample is concerned (and including the former spouses of the divorced w.F.M.), 14 (65\%) were university professors and 6 (35\%) practised higher private professions ( 2 doctors, 3 civil engineers and 1 chemical engineer).

Focusing our interest on the academic background of the w.F.M. in the sample we should point out that: 1) 14 (70\%) graduated from public (state) schools and 6 (30\%) from private schools, 2) 18 w.F.M. graduated from one of the three largest Greek universities ( 9 from the University of Athens, 3 from the University of Thessaloniki and 6 from the University of Patras) and 2 from universities abroad, and 3) 10 w.F.M. gained their doctorate from the University of Patras and the other 10 from Universities abroad.

\subsection{Conducting the Research}

The choice of the sample was made using the method of snowball sampling ([37], pp. 173-174 [38], p. 372) during which our initial contact with the w.F.M. led us to others. This was because we ran into difficulties in getting a response from the w.F.M. due to lack of time and an unwillingness to participate in this research. We met the w.F.M. in the sample in their offices at the University of Patras after the meeting had been arranged by telephone. Prior to each interview we explained the aim of our research and requested permission to use a tape recorder. This was because we wanted to be careful not to miss out information and to note down at the same time non-linguistic elements (such as hesitation, intonation or silences) which would be useful during the interpretation of our data. The research took two months to complete and each interview lasted about one hour. We tried to make sure that the women we interviewed came from a wide range of university fields so that we could locate any differentiations in their views.

After completion of the interviews, we proceeded to their transcription and the qualitative analysis of their content, taking as unit of analysis the topic with the objective of searching for the meaning of the w.F.M.'s experiences in the field of the University of Patras [33] [34] [36]. More precisely, the topic concerns the "basic idea that is developed either in part of the text (sentence, paragraph) or in the whole of the text of the analyzed interviews" and the reason we chose it as a unit of analysis and recording is because it is used in studies which centre on the investigation of values, attitudes and opinions ([32], p. 291).

Then, the various topics were classified into specific analysis categories for analysis which emerged in an inductive fashion, taking into consideration the research questions, theoretical framework and purpose of the research ([35], pp. 232-236).

\section{Presentation and Analysis of the Research Data}

The field of research is the University of Patras which was established in 1964 and is the third Greek University in terms of year of establishment and size. In the academic year 2011-2012, when the research was carried out, the University of Patras consisted of 4 Schools (Sciences, Polytechnic, Health Sciences, Human and Social Sciences) and 2 Independent Departments (Business Administration and Economic Sciences).

From when the University of Patras started to operate, until 1978, no w.F.M. worked there. The first woman professor was appointed to the School of Physics and Maths in 1979. This situation began to change with the application of Law 1268/1982 [39] as it gave the opportunity to the auxiliary teaching staff who were working at the Universities, among whom there was a significant number of women, to take up positions as F.M. [40].

As far as distribution by sex and level of the w.F.M. of the University of Patras for the academic year 2011-2012 is concerned, the following emerge:

- w.F.M. constitute a minority since they hold 21.8\% of F.M. positions (158 women) while men hold $78.2 \%$ of university positions (569 individuals).

- The greatest concentration of w.F.M. in the academic hierarchy is to be observed at the levels of Assistant Professor and Associate Professor (56 women, 35.4\% and 40 women, 25.3\%, respectively). In the highest 
hierarchical level of Professors the proportion of women is lower (27 women, 17.1\% out of the total number of w.F.M.). Hence male F.M. make up the vast majority at professorship level (234 individuals, $89.6 \%$ of the total number of F.M.) as against w.F.M. (27 women, $10.4 \%$ of the total number of F.M. at the University of Patras).

In Table 1 the distribution of F.M. who were working during the academic year 2011-2012 in the University of Patras, by gender, grade and school, is presented.

From a study of the data in Table 1, the following emerge:

- The greatest concentration of w.F.M. is located, in descending order, in the Schools of Human and Social Sciences (47 women, $47.9 \%$ of the total number of F.M. in the School), Health Sciences (44 women, 24.7\% of the total number of F.M. in the School), Sciences (45 women, 21.8\%), Independent Economics Departments ( 5 women, $17.2 \%$ of the total number of F.M. in the school). Smaller is the presence of w.F.M. in the Polytechnic School (17 women, 7.9\% of the total number of F.M. in the School).

- The greatest percentage of w.F.M. in the two highest grades in the academic hierarchy (Associate Professor and Professor) is to be observed, in descending order, in the School of Human and Social Sciences (12 women, $16.1 \%$ of the total number of F.M. in the School), Health Sciences (26 women, 8.9\% of the total number of F.M. in the School), and the Sciences (17 women, 8.2\% of the total number of F.M. in the School). The presence of w.F.M. at the level of Associate Professor and Professor in the Polytechnic School is very small (5 women, $2.3 \%$ of the total number of F.M. in the School).

The above findings reveal that in the scientific field of the University of Patras, there is "horizontal and vertical discrimination" between the sexes in the academic profession. W.F.M. are concentrated mainly in the Humanistic and Social Sciences and are under-represented in the higher grades of the professorship hierarchy. In addition, they have a meagre presence in the Polytechnic School, which possesses high status and is characterized as a "male" orientation which on an international level is linked more generally to a university career [41] [42].

\subsection{The Socio-Economic and Educational Profile of the w.F.M. in the Sample}

The educational and professional characteristics of the families of the w.F.M. who participated in the research are as follows:

- The profession of 7 w.F.M.'s fathers (35\%) is in the scientific sector, 3 women's fathers (15\%) worked as administrative or secretarial staff in the public sector, 6 women's fathers (30\%) practiced trade or craft professions, 3 women's fathers (15\%) were military personnel and one woman's father (5\%) was a farmer. The professions of the w.F.M.'s mothers is distributed as follows: 4 (20\%) practiced a scientific profession, 2 (10\%) worked as administrative employees, in the public sector, one (5\%) was a farmer and 13 (65\%) said they were housewives.

Table 1. Faculty members in the university of patras according to schools, gender and grade during the academic year 2011-2012.

\begin{tabular}{|c|c|c|c|c|c|c|c|c|}
\hline \multirow{2}{*}{ Schools } & \multicolumn{2}{|c|}{ Professors } & \multicolumn{2}{|c|}{ Associate Professors } & \multicolumn{2}{|c|}{ Assistant Professors } & \multicolumn{2}{|c|}{ Lecturers } \\
\hline & Men & Women & Men & Women & Men & Women & Men & Women \\
\hline Natural Sciences & 70 & 6 & 26 & 11 & 50 & 17 & 15 & 11 \\
\hline Engineering & 96 & 1 & 37 & 4 & 45 & 6 & 20 & 6 \\
\hline Health Sciences & 49 & 10 & 30 & 16 & 42 & 14 & 14 & 4 \\
\hline $\begin{array}{c}\text { Humanities \& Social } \\
\text { Sciences }\end{array}$ & 15 & 8 & 14 & 8 & 11 & 17 & 12 & 14 \\
\hline $\begin{array}{l}\text { Independent } \\
\text { Departments of } \\
\text { Economy }\end{array}$ & 5 & 2 & 8 & 1 & 7 & 2 & 4 & 0 \\
\hline Total & 234 & 27 & 115 & 40 & 155 & 56 & 65 & 35 \\
\hline
\end{tabular}

Source: The general directorate for administrative services at the university of patras. 
- Eight w.F.M. (40\%) had a father who was a university graduate, of whom one had a doctorate, 3 women's fathers (15\%) had studied in a higher military school, 4 women's fathers (20\%) had completed secondary education, 2 women's fathers $(10 \%)$ had completed the first stage of secondary education and 3 women's fathers (15\%) had finished primary school. The mothers of 3 w.F.M. (15\%) had a university degree, and of whom one had a doctorate, 10 mothers (50\%) had completed their secondary education, one (5\%) had completed a 3 year lower secondary school, and 6 mothers (30\%) had completed primary education.

Consequently, the majority of w.F.M. who participated in the research came from middle-class families with adequate economic family capital and an average to high level of education.

Then, the institutionalized cultural capital of the 20 w.F.M. in the sample reveals that almost in their entirety (18 women, 90\%) they had completed their secondary education in schools which belonged to urban groupings of more than 100,000 inhabitants, 13 women (70\%) completed their secondary education in state schools and 6 (30\%) in private schools. In addition, 18 women $(90 \%)$ graduated from the three biggest Greek universities (Athens, Thessaloniki and Patras) and $2(10 \%)$ graduated from foreign universities. The postgraduate diplomas (Master, $\mathrm{PhD}$ ) of 10 women (50\%) were gained from greek universities and 10 (50\%) from universities abroad. Consequently, these particular w.F.M. had accumulated the necessary institutionalized cultural capital in the form of education titles which allowed them to enter the scientific field. In other words, this particular capital functions as the pre-required "passport" for entry into the field of the University of Patras ([22], p. 82 [24], p. 76).

\subsection{W.F.M.'s Entry into the Academic Field of the University of Patras}

From the narratives of the w.F.M. in the sample it seems that the academic field did not constitute for them a professional career objective. In fact, from the following excerpts, it emerges that under pressure from their parents they followed, initially, studies which correspond to the traditional attitudes concerning the role of women:

To begin with, my parents wanted me to become a teacher. They were always of the opinion that a good job is that of a teacher. I didn't know I'd be teaching in tertiary education... It wasn't my original objective. (Interview-I.1).

I achieved the grades to go to the Polytechnic. However my father didn't want to send me. I also passed the exams to become a teacher... and I went because my father's opinion was that you'll become a teacher because it is a job suited to women, but then I didn't stop, I continued... and I found myself in the academic environment. (I.16).

So, in the words of the w.F.M., male theorizing and dominance, which is reproduced in the family within which the division of labour by sex is taken on by the engendered subjects, is depicted ([29], p. 158). In this way, the choice of employment positions which seem to suit women since they constitute an extension of the domestic functions, is activated in the family environment ([29], p. 172). The job of teacher is presented as ideal since it maintains the social order of things in the world of the division of labour and corresponds to the action of the shaping (Bildung) of women's engendered habitus. So it seems that the entry of these particular women into the field of science where participation in the "games" is usually linked with masculinity was not set as an objective ([29], pp. 65, 113). That's why the choice of profession is characterized by its randomness, which is depicted in the testimonies of the w.F.M. below:

It was probably by chance that I ended up at the University. I wanted to become a teacher... When I got my degree a position for a scientific associate came up at the University and I got it. At that time the legal framework was being shaped and there were some transitional terms. (I.3).

By chance... I entered the university. I bumped into a former fellow student and he told me that the University was looking for scientific associates. That's how I started... (I.10).

In the words of the w.F.M. above the link between their access to the academic profession and the transitional clauses of Law 1286/1982 “On the structure and operation of the Higher Education Institutions” which gave women working as permanent auxiliary teaching staff the opportunity to be appointed to the level of lecturer and follow a university career, is clearly apparent ([16], p. 250).

Only one w.F.M. clearly stated her deliberate choice of a university profession: 
What you're asking me is multi-factored... to start with both my parents are in the academic field, university teachers. Then my husband who is also a University professor would have played a role too... (I.14).

From this response emerges the decisive influence the family environment had on this particular w.F.M.'s choice. Here it seems that the family functions as a "structuring principle" which is inherent in habitus, and guides the practical sense of its members ([43], p. 95). In addition it comprises the main space for the accumulation and transfer of forms of capital, which are inherent within it, and contributes to their maintenance by the descendants ([23], pp. 124-129), In the entry of this particular w.F.M. into the university field, it would appear that her marriage to a fellow academic made an ancillary contribution. Indeed, the phenomenon of nepotism is met in the global university field [44].

\subsection{W.F.M.'s Difficulties in the Academic Field}

From an analysis of the material in the interviews the following findings regarding the w.F.M.'s difficulties in the academic field of the University of Patras emerged.

\subsubsection{The Price of Integration into the Academic Field. an Inharmonic Meeting of Engendered Habitus and Field}

The dominant difficulty for the w.F.M. at the University of Patras appears to be the problem of balancing the demands of their lives in the private and public spheres. The neglect of their obligations as mothers and wives in favour of their career advancement in the university field constitutes the main sacrifice women have to make. The following comment is characteristic:

When you neglect your children for work, this becomes apparent later... I would not recommend an academic career to a woman whose first priority is her family. I think that when she decides to start a family she should have it as her first priority... A university career is demanding. I made sacrifices at the expense of my children and that isn't good. (I.3).

Another w.F.M., talking about the obstacles to the demands of the university profession, which are created by family obligations, claims:

Being a woman places some restrictions on you in this profession. In other words, many many times I didn't take transatlantic journeys to conferences because I had small children and there was no one to look after them. (I.15).

The co-existence of family obligations and professional demands in the academic field appears to create serious problems of conscience for w.F.M.:

It is a very big struggle to do the right thing at work and at home and certainly when women are at work they are thinking of the home and when they are at home they have feelings of guilt because they're not at work. It is a huge internal battle that cannot be won. (I.13).

From the above excepts the inharmonic meeting of a university position and the not suitably formed and adapted engendered habitus of the women regarding their participation in the game of the academic field emerges ([27], p. 138 [29], p. 116). The university profession does not blend well with the social role and functions of the particular women, in the family. In addition it does not blend well with the "objective aspirations" which are etched in an implicit way in the work positions. This is because the positions that are usually offered to, and taken on by women correspond to their feminine dispositions (engendered habitus) and at the same time they provide them with the necessary time to be able to carry out their roles as wives and mothers successfully ([29], p. 115 [45]).

\subsubsection{The Deficit in w.F.M.'s "Net" Scientific Capital}

The w.F.M. in the sample entered the male dominated field of the University of Patras with an initial "institutionalized cultural capital" in the form of titles, adequate for their successful entrance. The course of their advancement however in the academic grades depends upon the continuous accumulation of both of the "difficult to accumulate in practice" forms of scientific capital, namely the net and the institutional ([28], p. 43). In their responses, the difficulty of accumulating net scientific capital, and the view that w.F.M. publish less frequently 
than their male colleagues, is depicted. In fact, they attribute the phenomenon of their limited production of "scientific goods" in the form of article writing in authoritative journals, which bestow status and power, to difficulties which are linked to a lack of time for writing, the "aggressiveness" which they consider distinguishes their male colleagues and sex discrimination, which they feel exist in the particular scientific field ([26], pp. 103-104).

\subsubsection{The Lack of Time for the Production of "Publications"}

The lack of time which w.F.M. face in their difficult daily lives, due to their increased family obligations, seems to constitute a significant factor creating difficulties for the production of publications. Hence, they mention characteristically:

I have been put in charge of all the family. Whichever way we look at it, that's just the way things are in Greece... when the woman gets away from the family then the she will be very well. When I went to Italy I did some very good work. Here less. (I.2).

Writing is a question of time. A woman has a greater family burden in relation to men, I mean she takes the family upon herself. This makes it difficult to produce numerous articles... Consequently, just as in the grades, she'll get there later and she'll reach the necessary number of papers later. (I.5).

In their words, the w.F.M. give prominence to the engendered division of labour in the field of the family. So, it seems that despite their greater representation in the intellectual professions, such as that of F.M. in Greece, compared to the past, a very significant portion of "domestic labour" continues to fall exclusively to women. Even in those cases where the women have managed to take on a high position, it seems that they pay for their success in the professional field with limited success in the family field, or vice versa ([29], p. 177).

\subsubsection{Women's Timidity and Men's Aggression: Two Factors in the Production of “Net Scientific Capital"}

In the narratives of the w.F.M. we identified, in latent from, the explanation that the difficulty they face in the publication of scientific articles and hence their difficulty in accumulating "net scientific capital” is to be put down to timidity:

Perhaps women don’t publish because they are timid... perhaps they don't dare to send an article for publication... perhaps they're afraid of criticism. (I.1).

In contrast, the w.F.M. put the greater production of "net scientific capital" on the part of men down to the aggressiveness they believe distinguishes them and which bestows on them an important advantage within the university field:

I believe that men publish more easily... I believe it has to do with the aggressiveness a man has... in the sense of self-confidence. When I have worked with them they will take the initiative more quickly that we can publish an article. I have a lot of restraint. (I.4).

A man publishes more papers because objectively...his career is the main objective of his life. In contrast in women it has been cultivated that they can't behave aggressively. (I.13).

Consequently, the w.F.M., when comparing themselves with their male colleagues, ascribe to them as positive the attribute of aggression, which is cultivated through a "silent preparation" for the male sex (engendered habitus) ([29], pp. 104, 123). It seems that in the scientific field which constitutes a battle ground, the quality of male university professors' aggressiveness in contrast to the timidity of women functions as a scientific resource for the accumulation of "net scientific capital" ([26], p. 102). The above mean that if one of the most important weapons in the scientific struggle which takes place within the university field is the "accumulated net scientific capital”, the male university professors accumulate it more easily and consequently ensure more comfortably their residence, advancement and occupation of dominant positions in the University ([28], p. 38).

\subsubsection{Engendered Discrimination in the University Field as a Constraint in the Accumulation of "Net Scientific Capital"}

An additional difficulty for the w.F.M. concerning the production of publications was engendered discrimination: 
They always prefer male researchers... they are in better favour and receive better treatment... perhaps because everyone believes that if they invest in them they have a more certain route to an academic career. (I.10).

I had problems with some male colleagues... there are times when you can discern misogyny, let's say. They might try to cover it up, but it's there. When I was a lecturer I had to fight a lot to prove I was worth something with the publications too. (I.7).

A common point in the narratives is the discrimination some w.F.M. have suffered in the university field due to their sex, and which obstructs the accumulation of "net scientific capital". This discrimination is due to the "male domination" of the field, which however, in most cases, is not enforced in an obvious, inflexible and self-evident way, as in the past, but is covered up ([29], p. 164). So, w.F.M. as members of an elite but at the same victims of discrimination, face difficulties in the accumulation of "net scientific capital" and are lacking as far as the "weapons" that they need to possess in order to take part in the struggle in the scientific field which is defined by masculinity, are concerned ([29], p. 170). Their inadequate "net capital" results in their gathering limited "profits" within the academic field and despite the fact that they have a position of status, they are placed in dominated areas within the field ([26], p. 103 [29], p. 170).

\subsubsection{W.F.M.'s "Institutional Scientific Capital”: A Non-Existent Capital}

The occupation of administrative positions, which together with participation in scientific and examination committees, conferences, meetings and symposiums, comprise the constituent parts of "institutional scientific capital" doesn't appear to be an easy matter for w.F.M. Two elements dominate in terms of their non-occupation of administrative positions. The refusal to compete for such positions and the institutional prohibition on their occupying such positions due to the low level at which they are. We should point out that according to Law 1268/1982 only those in high grades (professor emeritus, professor) can be elected to the positions of chancellor, vice chancellor, deans of schools, department chairman and heads of sectors ([39], p. 143). From the total number of women F.M. in the sample, only two had been appointed to high positions in the administrative hierarchy. The first as Dean and the second as department chair.

In the extracts that follow it appears that the low grades in which many w.F.M. are to be found, together with their inadequate "net scientific capital" constitute obstacles to their participation in administration.

I'm at a low level, I can't compete for positions of power. I don't aspire to positions of power. I can't say the idea appeals to me. (I.1).

I am an assistant professor, so I don't have the opportunity to be a candidate for such positions... and it will be so demanding that it would be very difficult. (I.3).

From these particular claims of the w.F.M. it appears that the desire to compete for and occupy high positions of responsibility within the university field is absent. Indeed, the particular policies and strategies which are needed for the occupation of and participation in a high administrative position demand and presuppose time. Something which is absent in their everyday lives ([28], p. 43).

More specifically, in the case of the w.F.M. in the University of Patras it appears that their preferences and choices in the scientific field are guided by their engendered habitus as "principles for the production of practices” ([29], p. 76).

I'm not at all interested in a position of power. It's just my nature is like that. (I.2).

Never, never, never did I aspire to a position of power. First of all, I'm very bad at it. I don't like asserting power at all, not at all. (I.9).

No, I never aspired to a position of power, I can't say that it's in my plans for the future... I wouldn't rule it out completely... it's not something I'm interested in. You really have to go after it, sell yourself. Ah! And we're in a space which has been made chiefly by men for men... aggressiveness in men is more intense. (I.14).

In the w.F.M.'s responses regarding the taking on of positions of power, like administrative positions, there is hidden a form of "symbolic violence", which imposes "male domination" in the area of administration in the academic field, with the consent and acceptance of the women ([29], p. 30). 


\section{Discussion and Conclusions}

From the study and analysis of the research material we arrive at the following conclusions:

- The w.F.M. at the University of Patras, which is the third University in size in the country, are underrepresented (F.M. in 2011-2012: 78.2\% men, 21.8\% women). In addition the existence of "horizontal and vertical discrimination" between the sexes in the academic profession at the particular university is evident, as is confirmed by other research in the international field too [1] [12] [41] [42] [46]. So, the invisible structures which have, throughout history, defined the division of labour in the various sectors of the market, in other words the fields (here the scientific field of the University of Patras), continue to persist despite the progress which has been made in the case of women ([29], pp. 164, 191).

- The middle class origin of the w.F.M. at the University of Patras as well as their "institutionalized cultural capital" granted them the essential "institutional recognition", the objective guarantee, but also the "mark of distinction" so that they could pass through the "rite of passage ceremony" in the scientific field ([26], pp. 82-82 [29], p. 66). It was also apparent that the work connection of many w.F.M. at the University of Patras during the past as assistant staff contributed to their entry into the scientific field through the activation of particular clauses of Law 1269/1982 [39].

- From the views of the w.F.M. on their choice to follow a university career it appeared that this did not constitute their main professional orientation. They attributed their choice mainly to "randomness", revealing their engendered habitus in relation to the orientation of their professional choices (positions) in the social field ([29], p. 33 [43], p. 96).

- As far as the difficulties that the w.F.M. face in their professional career are concerned, a conflict was discerned between their traditional social role, and their professional role. It appears that the strict dedication, the increased time, the continuous keeping up-to-date and study, which the academic profession demands, comprise insurmountable difficulties in many of the cases, in the daily life of w.F.M. in the University of Patras. It is a finding which is supported by the findings of other research which focuses interest on the entrance into and academic progress of women in the international university field [5] [7] [11] [31] [45] [47]. Indeed, they entered a profession which is not consistent with the medium and mediatory professions in which even today most women who have gained a study title find an outlet ([29], p. 167). Hence, the w.F.M. at the University of Patras present a lower level of professional success as they move between two worlds. They move between a man's world, which was structured around the public productive sphere, and a female world structured around the reproductive sphere ([20], p. 328 [43]).

- The w.F.M. who participated in the research entered the male dominated university field with an initial, powerful "institutionalized cultural capital", sufficient for their successful entry. However, the procedure of accumulating scientific capital-net and institutional—did not seem to be easy for them. Hence, in the world of science, which is governed by power relations, social relations of domination, but also phenomena of the gathering of capital, w.F.M. do not appear to possess the suitable "weapons" in order to participate with high chances of success in the "game” of the scientific field ([28], p. 31). Moreover, they clearly state their limited interest in, or even rejection of, positions of power since access to such positions places them in a “double bind" situation. In other words, either they behave like men and thereby lose a part of their femininity, or they behave like women and find themselves on the sidelines, accumulating restricted "institutional cultural capital” ([29], p. 131). In this case the research findings agree with the findings of other research in the international academic field which show the limited ambitions and consequently the refusal of a great number of w.F.M. to go after positions of power in the academic field [7] [12] [48] [49]. Consequently, due to the limited volume size of their scientific capital the w.F.M. are placed in positions of the dominated, and not the dominating, in the structure of the scientific field.

This study was focused on a part of w.F.M. of the University of Patras (18.7\% of the female Academics by the grades of Professor, Associate Professor and Assistant Professor) who accepted to participate in our research. Consequently, the findings of this study are not generalized but are representative and revealing for the access and development of w.F.M. in the scientific field of the specific University. Indeed, it would be interesting to continue the present research effort in the academic field and particularly in the investigation of the entry, progress and difficulties of the w.F.M. in the various scientific fields in Greece, in comparison with other countries. 


\section{References}

[1] Acker, S. and Webber, M. (2006) Women Working in Academe: Approach with Care. In: Skelton, C., Francis, B. and Smulyan, L., Eds., Handbook of Gender and Education, Sage, London, 483-496. http://dx.doi.org/10.4135/9781848607996.n35

[2] Jackson, J. and O’Callaghan, E. (2009) What Do We Know about Glass Ceiling Effects? A Taxonomy and Critical Review to Inform Higher Education Research. Research in Higher Education, 50, 460-482. http://dx.doi.org/10.1007/s11162-009-9128-9

[3] Bebbington, D. (2001) Women Scientists in Higher Education: A Literature Review. Athena Project, London.

[4] European Technology Assessment Network [ETAN] (2001) Science Policies in the European Union: Promoting Excellence through Mainstreaming Gender Equality. ftp://ftp.cordis.lu/pub/etan/docs/women.pdf

[5] Siann, G. and Callaghan, M. (2010) Choices and Barriers: Factors Influencing Women’s Choice of Higher Education in Science, Engineering and Technology. Journal of Further and Higher Education, 25, 85-95. http://www.tandfonline.com/doi/abs/10.1080/03098770020030524

[6] Sanders, K., Willemsen, T. and Millar, C. (2009) Views from Above the Glass Ceiling: Does the Academic Environment Influence Women Professors' Careers and Experiences? Sex Roles, 60, 301-312. http://link.springer.com/article/10.1007/s11199-008-9547-7

[7] Bagilhole, B. (2002) Academia and the Reproduction of Unequal Opportunities for Women. Science Studies, 15, 4660 .

[8] Bagilhole, B. (2007) Challenging Women in the Male Academy: Thinking about Draining the Swamp. In: Cotterill, P., Jackson, S. and Wetherby, G., Eds., Challenges and Negotiations for Women in Higher Education, Springer, Dordrecht, 21-32. http://dx.doi.org/10.1007/978-1-4020-6110-3_1

[9] Van Anders, S.M. (2004) Why the Academic Pipeline Leaks: Fewer Men than Women Perceive Barriers to Becoming Professors. Sex Roles, 51, 511-521. http://link.springer.com/article/10.1007/s11199-004-5461-9 http://dx.doi.org/10.1007/s11199-004-5461-9

[10] Bandle, C. and Wilhelm, J. (2007) Empowering Women Academics in a Global Society: The Glass Ceiling. Papers Presented in the 29th IFUV Conference, Manchester. http://www.ifuw.org/wp-content/uploads/2014/01/bandle-wilhelm.pdf

[11] Monroe, K., Ozyurt, S., Wrigley, T. and Alexander, A. (2008) Gender Equality in Academia: Bad News from the Trenches, and Some Possible Solutions. Perspectives on Politics, 6, 215-233. http://dx.doi.org/10.1017/S1537592708080572

[12] Acker, S. (2010) Gendered Games in Academic Leadership. International Studies in Sociology of Education, 20, 129-152. http://www.tandfonline.com/doi/abs/10.1080/09620214.2010.503062 http://dx.doi.org/10.1080/09620214.2010.503062

[13] Carvalho, T. and Santiago, R. (2010) Still Academics after All. Higher Education Policy, 23, 397-411. http://dx.doi.org/10.1057/hep.2010.17

[14] EL.STAT. (Greek Statistical Authority) (2013) Statistics for Higher Education. Students, Institutions and Educational Staff at the End of the Academic Year 2010/2011. http://www.statistics.gr/portal/page/portal/ESYE/BUCKET/A1403/PressReleases/A1403_SED33_DT_AN_00_2010_0 1L_F_GR.pdf

[15] Assimaki, A., Koustourakis, G. and Papaspyropoulou K. (2012) Female Faculty Members in the Field of Electrical and Computer Engineering: The Case of Greek Universities. Problems of Education in the $21^{\text {st }}$ Century, 39, 15-28. http://oaji.net/articles/2014/457-1408437112.pdf

[16] Maragoudaki, E. (2008) Women University Teachers: Developments and Consistencies in Their Position in the Academic Space. In: Kastrani, T., Lentza, V., Petridou, K. and Frosi, L., Eds, Minutes of the Kallirroi Conference, From Adolescence to Adult Life, Aristotle University of Thessaloniki, Thessaloniki, 239-270.

[17] Vosniadou, S. and Vaiou, L. (2008) Engendered Inequalities in the Scientific Staff of the University of Athens. In: Vosniadou, S., Ed., Confronting the Engendered Inequalities in the Universities, University of Athens, Athens, 6-14.

[18] Sianou-Kyrgiou, E. (2010) From the University to the Job Market. Metaichmio, Athens.

[19] Stratigaki, M. (2003) Policies for the Equality of the Sexes in the European Union: Coincidences and Contrasts in the Course of the European Union. In: Panagiotopoulou, R., Koniordos, S. and Maratou-Alibranti, L., Eds, Globalization and Contemporary Society, EKKE, Athens, 175-188.

[20] Arnot, M. (2006) Reproducing Gender? Essays on Educational Theory and Feminist Politics. Metaichmio, Athens.

[21] Reay, D., David, M.E. and Ball, S. (2005) Degree of Choice. Social Class, Race and Gender in Higher Education. Trentham Books, London. 
[22] Bourdieu, P. (1994) Texts on Sociology. Delfini, Athens.

[23] Bourdieu, P. (2000) Practical Reason: On the Theory of Action. Plethron, Athens.

[24] Bourdieu, P. and Wacquant, L. (1996) An Invitation to Reflexive Sociology. Polity Press, Cambridge.

[25] Bæck, U.-D.K. (2010) "We Are the Professionals”: A Study of Teachers' Views on Parental Involvement in School. British Journal of Sociology of Education, 31, 323-335. http://www.tandfonline.com/doi/abs/10.1080/01425691003700565 http://dx.doi.org/10.1080/01425691003700565

[26] Bourdieu, P. (1992) Microcosms. Three Field Studies. Delfini, Athens.

[27] Bourdieu, P. (2007) The Science of Science and Reflexivity. Pataki, Athens.

[28] Bourdieu, P. (2005) On Science and Its Social Uses. Polytropon, Athens.

[29] Bourdieu, P. (2007) Masculine Domination. Patakis, Athens.

[30] MacLeod, J. (2005) Feminists Re-Reading Bourdieu: Old Debates and New Questions about Gender Habitus and Gender Change. Theory and Research in Education, 3, 95-117. http://dx.doi.org/10.1177/1477878505049832

[31] Ward, L. (2008) Female Faculty in Male-Dominated Fields: Law, Medicine and Engineering. New Directions for Higher education, 143, 63-72. http://dx.doi.org/10.1002/he.314

[32] Kyriazi, N. (2006) Sociological Research. Hellenika Grammata, Athens.

[33] Shank, G. (2002) Qualitative Research. A Personal Skills Approach. Merril Prentice Hall, Upper Saddle River.

[34] Mason, J. (2002) Qualitative Researching. 2nd Edition, Sage, London.

[35] Paillé, P. and Mucchielli, A. (2008) L'analyse qualitative en sciences humaines et socials. Armand Colin, Paris.

[36] Robson, C. (2006) Research of the Real World. Gutenberg, Athens.

[37] Cohen, L., Manion, L. and Morrison, K. (2008) The Methodology of Educational Research. Metaichmio, Athens.

[38] Mertens, D. (2009) Research and Assessment in Education and Psychology. Metaichmio, Athens.

[39] Benos, S. (2008) Law 1268/82 and Subsequent Regulations for I.H.E. E. Benou, Athens.

[40] Asimaki, A., Katsigianni, M. and Koustourakis, G. (2008) The Defining Factors in the Development of the Position of Women in the Academic (University) Hierarchy. Case Study: The University of Patras 1964-2007. http://www.eriande.elemedu.upatras.gr/?section=985\&language=\%20el GR\&page706=\%201\&print=1itemid706=1073

[41] Berggren, C. (2008) Horizontal and Vertical Differentiation within Higher Education-Gender and Class Perspectives. Higher Education Quarterly, 62, 20-39. http://dx.doi.org/10.1111/j.1468-2273.2008.00381.x

[42] Poole, M., Bornholt, L. and Summers, F. (2006) An International Study of the Gendered Nature of Academic Work: Some Cross-Cultural Explorations. Higher Education, 34, 373-396.

http://link.springer.com/article/10.1023/A:1003075907126 http://dx.doi.org/10.1023/A:1003075907126

[43] Bourdieu, P. (2006) The Logic of Practice. Alexandreia, Athens.

[44] Abramo, G., D’Angelo, C.A. and Rosati, F. (2014) Career Advancement and Scientific Performance in Universities. Scientometrics, 98, 891-907. http://link.springer.com/article/10.1007/s11192-013-1075-8 http://dx.doi.org/10.1007/s11192-013-1075-8

[45] Mickelson, R.A. (2003) Gender, Bourdieu and the Anomaly of Women’s Achievement Redux. Sociology of Education, 76, 373-375. http://dx.doi.org/10.2307/1519873

[46] Giacometti, M. (2002) Women in Italian Universities. Industry and Higher Education, 16, 43-48. http://dx.doi.org/10.5367/000000002101296072

[47] Toren, N. (2001) Women in the Academe: The Israeli Case. International Journal of Sociology and Social Policy, 21, 50-56. http://dx.doi.org/10.1108/01443330110789565

[48] Baghihole, B. and White, K. (2008) Towards a Gendered Skills Analysis of Senior Management Positions in UK and Australian Universities. Tertiary Education and Management, 14, 1-12. http://www.tandfonline.com/doi/abs/10.1080/13583880701814124 http://dx.doi.org/10.1080/13583880701814124

[49] Cubillo, L. and Brown, M. (2003) Women into Educational Leadership and Management: International Differences? Journal of Educational Administration, 41, 278-291. http://dx.doi.org/10.1108/09578230310474421 